\title{
FALLING CAPACITY UTILIZATION OF THERMAL POWER PLANTS IN INDIA: PROJECTION OF FUTURE SCENARIOS
}

\author{
ALOK K. TRIPATHI \\ NTPC Regional Learning Institute, Western Region II, \\ Bilaspur, Chhattisgarh, India.
}

\begin{abstract}
The utilisation factor of coal-based thermal power plants in India is consistently falling. The average national capacity utilisation factor, commonly known as plant load factor (PLF), has dwindled from $78.6 \%$ in $2007-08$ to $56.01 \%$ in $2019-20$. Several highly efficient and modern power plants are destined to run at very low PLFs. On top of this, 59,810 MW of new and advanced technology thermal power plants are in pipeline. These plants are also likely to experience dismally low capacity utilisation. All this is happening even when unmet power demand exists in the country and coal-based thermal power is still the mainstay of power generation. Falling PLF of the plants is therefore a matter of concern for all the stakeholders. It is important to know what future has in store for these plants. Partial least square (PLS) regression has been used for projection of PLF for the next five years and five likely scenarios have been created. Projections show that in the business as usual case (factors increasing at the current CAGR rate; Scenario I), the thermal power plants will face very low level of PLF $(14.76 \%)$ by $2024-25$. This leads to a grim situation. However, it was found that in one of the scenarios, that is, fuel mix and demand as per Central Electricity Authority's (CEA) suggestions with phasing out of old plants, Scenario V, the average PLF can be sustained above 68\% until 2024-25. If this path is followed, thermal plants will get a fresh lease of life, at least in the medium term. It will also give time to policymakers and utilities to prudently plan the optimum generation mix in the country including thermal and renewable energy.
\end{abstract}

Keywords: capacity utilisation, future outlook, generation mix, India, PLF, thermal power plants.

\section{INTRODUCTION}

\subsection{Falling plant utilisation of thermal power plants in India}

The plant utilization factor, known more commonly as plant load factor (PLF), has been coming down consistently in India. Table 1 depicts how national average PLF of coal-based stations has fallen from $77.5 \%$ in $2009-10$ to $56.01 \%$ in $2019-20$.

It is also pertinent to note that the drop in PLF is happening across the sectors, i.e. central, state and private sector. It can also be seen that central sector plants have maintained the highest PLF, followed by private and state sectors. On average basis (taking the average of 11 years data), central sector plants have maintained a higher PLF than the national PLF by about $10.08 \%$, the state sector is lower than the national PLF by $5.55 \%$ and the private sector PLF is lower by $2.13 \%$.

Under this situation, another 59,810 MW of new thermal power generation capacity is under construction in the country. Out of this, 23,730 MW is under the private sector, 18,320 MW is under the central government sector and 17,760 MW is under the state government sector as reported by PTI in The Economic Times on 16 September 2020 [6]. It is evident that all the three sectors are adding capacities. 
Table 1: Sector wise and national average PLF of thermal power plants in India 2009-10 to 2019-20.

\begin{tabular}{lllcc}
\hline & & \multicolumn{3}{c}{ Sector-wise PLF (\%) } \\
Year & National PLF \% & Central & State & Private \\
\hline $2009-10$ & 77.5 & 85.5 & 70.9 & 83.9 \\
$2010-11$ & 75.1 & 85.1 & 66.7 & 80.7 \\
$2011-12$ & 73.3 & 82.1 & 68.0 & 69.5 \\
$2012-13$ & 69.9 & 79.2 & 65.6 & 64.1 \\
$2013-14$ & 65.60 & 76.10 & 59.10 & 62.10 \\
$2014-15$ & 64.46 & 73.96 & 59.83 & 60.58 \\
$2015-16$ & 62.29 & 72.52 & 55.41 & 60.49 \\
$2016-17$ & 59.88 & 71.98 & 54.35 & 55.73 \\
$2017-18$ & 60.67 & 72.35 & 56.83 & 55.32 \\
$2018-19$ & 61.07 & 72.64 & 57.81 & 55.24 \\
$2019-20$ & 56.01 & 65.36 & 50.26 & 54.73 \\
Average of last & 65.99 & 76.07 & 60.43 & 63.85 \\
11 years & & & & \\
\hline
\end{tabular}

Source: Government of India, Ministry of Power and Central Electricity Authority (CEA) [1-5].

With PLFs already low for existing players, this upcoming capacity also runs the risk of very low capacity utilisation.

Apparently, there are a couple of reasons behind the continued thermal capacity addition despite the falling utilisation factor. One reason is the capacity planning process itself. There has been a strong, persistent view that the future power demand of the country cannot be served by renewables and hence thermal capacity must be added. Even the Central Electricity Authority (CEA), the apex government body responsible for planning in the power sector, in its national electricity plan of 2018 (NEP 2018) [7] acknowledged that 47,885 MW capacity plants were under construction in 2018 and further projected the need for 46,420 MW of thermal capacity between 2022 and 2027. Such projections were partly based on assumptions of power demand fuelled by high growth rate of GDP (6.98\% GDP growth rate was assumed from 2020-21 through 2026-27 in the CEA NEP 2018). However, such growth could not actually materialise. The revised estimate for GDP growth rate for 2019-20 was only 4\% as reported by the Mint on 29 January 2021 [8]. Such changes do not seem to be dynamically captured in the planning process. Corroborating this view, The Financial Express, a prestigious newspaper in the country (20 April 2020) [9], reported that there has been a substantial error in power demand forecasting in the country and overestimated GDP figures have been used as input.

Since thermal power plants are high gestation period projects (4-5 years), once a planning input goes into drawing board, and plants start taking shape, it is tough to backtrack the process. Substantial amount of money, land and time already gets committed to the projects. 
Another probable reason why the developers are able to take the risk of adding fresh thermal capacity is the inbuilt safety of return on equity guaranteed by the electricity tariff and long-term power purchase agreements (PPAs). Electricity prices are regulated in India with a two-part tariff comprising fixed and variable charges. For inter-state power plants (supplying power beyond a state, which most large thermal power stations do), there is provision of $15.5 \%$ return on equity inbuilt in the tariff as per Central Electricity Regulatory Commission's (CERC) notification (7 March 2019) [10]. The power procurer, usually a state distribution utility, typically enters into a long-term power purchase agreement (PPA), spanning 25 years, with the power plant developer. By the provision of regulated tariff, the procurer guarantees to pay to the developer a return @ 15.5\% on invested equity plus the interest on debt as a part of fixed cost throughout the period of the PPA. This provision has indeed served very well in the past, helped the thermal sector grow, attracted much needed investment in the capital-intensive sector and brought certainty in the high-risk environment. However, the provision also seems to have unintentionally induced utilities to go overboard and create overcapacity.

Over-reliance on coal-based plants also appears to have happened due to the fact that gasbased combined cycle plants did not take off well due to non-availability of gas in the country. The non-availability of domestic gas and high cost of imported supply has 'stranded' gasbased power plants with a capacity of 14,305 megawatts, reports Kiran Pandey, in Down to Earth (17 January 2019) [11]. Coal plants have gone ahead to bridge this gap as well.

Even as the coal plants were getting set up in anticipation of demand, renewable energy has caught up faster than expected, both in terms of installed capacity and in terms of electricity price parity. The advent of renewables at a fast pace also appears to be responsible for the present situation being faced by thermal plants. India is progressing well on the path of having $175 \mathrm{GW}$ of renewable energy by 2022, which includes $100 \mathrm{GW}$ from solar, $60 \mathrm{GW}$ from wind, $10 \mathrm{GW}$ from bio-mass and $5 \mathrm{GW}$ from small hydro-power. In terms of price parity, the recent discovered prices of solar energy have touched the level of less than INR 3 (4 US cents) per kilowatt hour, a tariff that coal-fired generators have difficulty matching, reports Clyde Russell (Reuters, 20 February 2019) [12]. In addition to solar and wind power, biomass is also emerging as a competitor for conventional coal-based thermal power. India has a potential of about $18 \mathrm{GW}$ of energy from biomass report Sharma and Soltendieck, Embassy of Denmark [13].

Coal capacity appears to have been caught up between inaccuracies of forecasting, obsession with legacy systems and fast advent of renewables. The matter of our concern in this paper is that having built the thermal power plants with huge investments based on planning inputs, long-term PPAs and a supporting tariff structure, it is in the interest of all the key stakeholders to see that the capacity utilisation is high enough to sustain viability. Our attempt is to find out what direction thermal power utilisation will take in future so that necessary policy changes can be made for optimum generation mix in the country keeping sustainable development goals in view.

\subsection{The business problem}

When plants run at low capacities, their efficiency parameters worsen. If a modern, high-efficiency plant runs at lower capacity and hence at lower efficiency, it defeats the purpose of setting up new high-efficiency plants. Moreover, there is high likelihood that the power producer suffers financial losses in the form of under recovery of cost of generation and loss of generation incentive. 
Lower PLF means that plants are running with operating parameters worse than design/ normative limits (norms fixed by the electricity regulator). The normative limits were fixed based on design values, which could be achieved only when plants run near full load. The energy charge (variable charge) that the thermal power generator receives through tariff is based on presumption that the plant is running at the specified heat rate level (normative level). When a plant runs at low PLF, the heat rate is higher than the normative level. This means that the producer will spend more on fuel but will get remunerated for lesser amount through the energy charge rate (ECR). Realising this difficulty, at the representation of thermal power generators, the regulator has permitted some allowance in the normative heat rate so as to compensate the generators for such loss, and has also introduced alternative mechanisms for sale of power like security constrained economic dispatch (SCED) and real time market (RTM). However, these measures are also not proving adequate as the PLF is going down day by day (in 2020-21, the national PLF till December 2021 was $51.49 \%$ [3]). Such a situation is obviously putting many power plants under great distress. In this paper, what path PLF will take in future is explored and five different scenarios are plotted.

\subsection{Literature review}

Many articles have been published in reputed magazines in India wherein prediction of future PLF has been made. In countries like China, scholarly research has also been made for predicting the future capacity utilisation of thermal power plants.

One of the most relevant work is by Wang and $\mathrm{Li}$ [14]. They have done a scenario analysis in the electric power industry in China under the implementation of the electricity market reform and a carbon policy in China. In another paper from China, Wang and Chen [15] have addressed the issue of continuous reduction in utilisation of thermal power capacity in China. They have studied the interaction between installed capacity and utilization of power sector into the dynamic spatial Durbin model. Another relevant work is from the United States wherein Smith [16] has analysed hourly generation patterns of large coal-fired units and the implications of transitioning from baseload to load-following electricity supplier. There is one very important reference work which comes from the apex planning body in the power sector in India, the Central Electricity Authority (CEA), the draft national electricity plan, volume I wherein it discusses the issue of capacity utilization of thermal power plants in India $[17,18]$. It has predicted that, by 2022 , many plants may get partial or no schedule of generation at all, meaning that many of these thermal power plants may have to be kept idle for lack of demand. There are also many articles from prestigious news publications in India which have reported that the utilization factor (PLF) of thermal power plants in India is going down and is likely to drop further. They have also brought out some of the factors behind such drop in utilization factor. Sengupta (The Economic Times, 20 December 2016) [19] predicts that thermal power plants' capacity utilisation in India will drop to $48 \%$ by 2022.

Although several articles have touched this issue in India, there is no published scholarly work to the best of the author's knowledge, where projection of PLF for the next 5 years has been made in the Indian context. This work is therefore novel in this arena.

\section{METHODOLOGY}

For prediction of future PLF, regression analysis was first deployed using Excel then a switch over to partial least square regression analysis (using R) was made. Initially, the regression was run using Excel with three factors as independent variables (these factors have emerged 
from literature review). The three factors (independent variables) considered are (i) peak power demand (MW), (ii) installed power capacity (coal) (MW) and (iii) total installed capacity of renewable energy (MW). PLF is taken as the dependent variable. Last 35 years' time series data of these variables are taken for the regression. Table 2 presents the data on which regression has been run.

Table 2: Year wise data- showing Peak Demand, Installed Capacity of Coal and Lignite, Total Installed Capacity of Renewables and PLF- Period 1985-86 to 2019-20 (Last 35 Years).

\begin{tabular}{|c|c|c|c|c|}
\hline Year & $\begin{array}{l}\text { Peak Demand } \\
(\mathrm{MW})(\mathrm{a})\end{array}$ & $\begin{array}{l}\text { Installed Capac- } \\
\text { ity Coal and } \\
\text { Lignite MW (b) }\end{array}$ & $\begin{array}{l}\text { Total Renewable } \\
\text { Energy capacity } \\
(\mathrm{MW})(\mathrm{c})\end{array}$ & PLF\% \\
\hline $1985-86$ & 28090 & 28809 & 0 & 52.4 \\
\hline $1986-87$ & 30850 & 30394 & 0 & 53.2 \\
\hline $1987-88$ & 31990 & 34237 & 0 & 56.5 \\
\hline $1988-89$ & 36245 & 37943 & 0 & 55.0 \\
\hline $1989-90$ & 40385 & 41510 & 0 & 56.5 \\
\hline 1990-91 & 44005 & 43379 & 18 & 53.9 \\
\hline 1991-92 & 48055 & 44791 & 32 & 55.3 \\
\hline 1992-93 & 52805 & 46597 & 79 & 57.1 \\
\hline 1993-94 & 54875 & 49147 & 185 & 61.0 \\
\hline 1994-95 & 57530 & 52139 & 576 & 60.0 \\
\hline 1995-96 & 60981 & 53547 & 820 & 63.0 \\
\hline 1996-97 & 63853 & 54154 & 940 & 64.4 \\
\hline 1997-98 & 65435 & 55969 & 992 & 64.7 \\
\hline 1998-99 & 67905 & 57483 & 1095 & 64.6 \\
\hline 1999-00 & 72669 & 59187 & 1167 & 67.3 \\
\hline $2000-01$ & 74872 & 60890 & 1407 & 69.0 \\
\hline $2001-02$ & 78441 & 62131 & 1702 & 69.9 \\
\hline 2002-03 & 81492 & 63800 & 2483 & 72.2 \\
\hline 2003-04 & 84574 & 64955 & 2980 & 72.7 \\
\hline 2004-05 & 87906 & 66416 & 3812 & 74.8 \\
\hline 2005-06 & 93255 & 68433 & 6191 & 73.6 \\
\hline 2006-07 & 100715 & 71121 & 7760 & 76.8 \\
\hline $2007-08$ & 108866 & 75002 & 11125 & 78.6 \\
\hline 2008-09 & 109809 & 77649 & 13242 & 77.2 \\
\hline
\end{tabular}




\begin{tabular}{lllll}
\hline $2009-10$ & 119166 & 84198 & 15521 & 77.5 \\
$2010-11$ & 122287 & 92378 & 18454 & 75.1 \\
$2011-12$ & 130006 & 112022 & 24504 & 73.3 \\
$2012-13$ & 135453 & 130221 & 27542 & 69.9 \\
$2013-14$ & 135918 & 145273 & 31692 & 65.6 \\
$2014-15$ & 148166 & 164636 & 35777 & 64.5 \\
$2015-16$ & 153366 & 185172 & 45924 & 62.3 \\
$2016-17$ & 159542 & 192163 & 57260 & 59.9 \\
$2017-18$ & 164066 & 197171 & 69022 & 60.7 \\
$2018-19$ & 177022 & 200704 & 77641 & 61.1 \\
$2019-20$ & 183804 & 205135 & 86759 & 56.08 \\
\hline
\end{tabular}

Source: Ministry of Power (MOP), Govt of India, various annual reports of CEA [1-5].

There is no missing data in the set. Since there are three independent variables in our study, at least 30 data sets are needed to run the regression (Peter's rule of thumb). Here, 35 data sets have been taken which is sufficient.

\subsection{Regression analysis}

The regression process was first carried out with the ordinary least squares method (using Excel software) and the coefficients of independent variables were found out. The $R^{2}$ and adjusted $R^{2}$ values obtained were 0.94 and 0.93 respectively showing an excellent fit. However, when the data set was tested for multicollinearity, it was found that the $\mathrm{X}$ variables (independent variables) had high correlation, despite all the $\mathrm{X}$ variables being individually significant. Since the main aim of this study is prediction of PLF (\%), multicollinearity could have been ignored. However, in order to make the projection more robust, it was decided to use the partial least square (PLS) method using R. This method helps reduce the number of predictors to a smaller set of uncorrelated components while retaining the impact of all the variables on $Y$ (dependent variable). The PLS method works by attempting to maximise the covariance in orthogonal space between $X$ scores (T components) and $Y$ scores (U components), rather than the variables themselves. Consequently, it does not suffer from the same assumptions concerning data structure as multiple linear regression modelling. It is therefore well suited to time-series data, which are typically characterised by high degrees of covariance among independent variables. In the present PLS model, two components were chosen based on root mean square error of prediction (RMSEP) criterion, wherein the number of components for which RMSEP gets minimised is chosen as a principle. The results were verified by using SelectNcomp function in R, which suggests the optimal number of components. The results of the RLS regression using $\mathrm{R}$ are given below, cross-validated using 10 random segments.

\begin{tabular}{lllll}
\hline & (Intercept) & 1 comps & 2 comps & 3 comps \\
\hline $\mathrm{CV}$ & 8.123 & 7.641 & 2.315 & 2.373 \\
$\operatorname{adjCV}$ & 8.123 & 7.775 & 2.294 & 2.347 \\
\hline
\end{tabular}


Table 3: PLS regression results.

\begin{tabular}{|c|c|c|}
\hline & Estimate & Std. Error Df \\
\hline 'Peak Demand (MW) (a)' & $4.9721 \mathrm{e}-04$ & $2.1977 \mathrm{e}-059$ \\
\hline $\begin{array}{l}\text { 'Installed Capacity Coal\& } \\
\text { Lignite MW (c)`' }\end{array}$ & $-2.6945 e-04$ & $1.7985 \mathrm{e}-059$ \\
\hline $\begin{array}{l}\text { 'Total Renewable Energy } \\
\text { capacity (MW) (d)' }\end{array}$ & $-2.7133 e-04$ & $5.0504 \mathrm{e}-059$ \\
\hline$t$ value $\operatorname{Pr}(>|t|)$ & 19.3310 & $1.225 \mathrm{e}-08 * * *$ \\
\hline \multicolumn{3}{|l|}{ 'Peak Demand (MW) (a)' } \\
\hline $\begin{array}{l}\text { 'Installed Capacity Coal\& } \\
\text { Lignite MW (c)`' }\end{array}$ & -10.5141 & $2.354 \mathrm{e}-06 * * *$ \\
\hline $\begin{array}{l}\text { 'Total Renewable Energy } \\
\text { capacity }(\mathrm{MW})(\mathrm{d}) `\end{array}$ & -4.2378 & $0.002181 * *$ \\
\hline \multicolumn{3}{|c|}{ Signif. codes: 0 ‘***’ 0.001 “**’ 0.01 '*’ 0.05 ', 0.1 ' ' 1} \\
\hline
\end{tabular}

Source: Regression using R.

A 10-fold cross validation is most common approach and the same is used in this study to select the two-component model. The results of the model show that RMSEP is getting minimised at two components, hence two components in the model are used. The two components explain $93.85 \%$ of the variance in the dependent variable, presenting a good fit.

Further, in order to obtain the PLS equation, this paper uses the Jack-knife test in R. The results shown in Table 3 are obtained after using Jack-knife test.

The $t$-values are significant and $p$-values are very small at $99 \%$ confidence level indicating that the model estimates are significant.

\section{RESULTS: FUTURE PLF PREDICTIONS}

Using the partial least square (PLS) regression (using R), the utilisation factor (PLF) has been projected for next five years (i.e. 2020-21 to 2024-25) and five scenarios have been projected. The national PLF obtained using PLS regression has been bifurcated for central, state and private sectors by adding the average historical difference that has been maintained in the past between national PLF and these segments (refer to Table 1). Presented in Table 4 is the result of regression showing projected PLF for the next five years in five different scenarios. Each scenario is based on certain assumptions about the independent variables which are described in the table.

\subsection{Discussion on results}

In both the scenarios I and II (BAU and RG), the PLF drops to as low as 38.6\% by 2022-23 itself. This is a worrying situation and indicates that in business as usual (BAU) or reduced growth (RG) scenarios, the thermal power plants may face major crisis as early as 2022-23. Looking at sector-wise position, in 2022-23, under Scenario I (BAU), the central sector plants will be reaching a PLF of $48.68 \%$. The state and private sectors will be running at $33.15 \%$ and $36.56 \%$ respectively. By 2024-25, in Scenario I, (BAU), the national PLF will reach abysmally low to $14.76 \%$. Central, state and private sector will touch $24.75 \%, 9.22 \%$ 
Table 4: Results of regression: Predicted PLF for five years.

\begin{tabular}{|c|c|c|c|c|c|c|c|}
\hline $\begin{array}{l}\text { CAGR \%l } \\
\text { Year }\end{array}$ & $\begin{array}{l}\text { Peak } \\
\text { Demand } \\
(\mathrm{MW})\end{array}$ & $\begin{array}{l}\text { Installed } \\
\text { Capacity } \\
\text { Coal (MW }\end{array}$ & $\begin{array}{l}\text { Renewable } \\
\text { Capacity } \\
\text { (MW) }\end{array}$ & Projected & LF \% S & tor Wis & \\
\hline \multicolumn{8}{|c|}{$\begin{array}{l}\text { Scenario I: Business as Usual (BAU) - Future values of all the three independent vari- } \\
\text { ables projected as per CAGR of last five years }\end{array}$} \\
\hline CAGR \% & 5.50 & 9.04 & 23.03 & National & Central & State & Pvt \\
\hline $2020-21$ & 193911 & 223674 & 106742 & 54.06 & 64.05 & 48.52 & 51.93 \\
\hline $2021-22$ & 204574 & 243888 & 131327 & 47.25 & 57.24 & 41.70 & 45.11 \\
\hline $2022-23$ & 215823 & 265928 & 161574 & 38.69 & 48.68 & 33.15 & 36.56 \\
\hline $2023-24$ & 227691 & 289961 & 198788 & 28.02 & 38.01 & 22.48 & 25.89 \\
\hline $2024-25$ & 240211 & 316166 & 244574 & 14.76 & 24.75 & 9.22 & 12.63 \\
\hline
\end{tabular}

Scenario II: Reduced Growth (RG) - Peak Demand, Coal Based Capacity and the Renewable Energy Capacity - CAGR of each one reducing by $3 \%$ (as compared to last 5 years' CAGR) due to Corona and other factors

$\begin{array}{llllllll}\text { CAGR \% } & 2.50 & 6.04 & 20.03 & \text { National } & \text { Central } & \text { State } & \text { Pvt } \\ 2020-21 & 188397 & 217520 & 104139 & 53.68 & 63.68 & 48.14 & 51.55 \\ 2021-22 & 193105 & 230652 & 125000 & 46.83 & 56.82 & 41.28 & 44.69 \\ 2022-23 & 197930 & 244577 & 150041 & 38.68 & 48.67 & 33.14 & 36.55 \\ 2023-24 & 202876 & 259343 & 180097 & 29.01 & 39.00 & 23.46 & 26.87 \\ 2024-25 & 207946 & 275000 & 216175 & 17.52 & 27.51 & 11.97 & 15.39\end{array}$

Scenario III: Low Coal and Aggressive Renewable (LCAR) - Growth rate of Thermal Capacity reducing by $5 \%$ and that of Renewable Capacity increasing by $2 \%$ (as compared to last 5 years' $C A G R$ )

$\begin{array}{llllllll}\text { CAGR } & 5.50 & 4.04 & 25.03 & \text { National } & \text { Central } & \text { State } & \text { Pvt } \\ 2020-21 & 193911 & 213417 & 108477 & 56.36 & 66.35 & 50.81 & 54.22 \\ 2021-22 & 204574 & 222033 & 135631 & 51.97 & 61.96 & 46.42 & 49.83 \\ 2022-23 & 215823 & 230997 & 169583 & 45.93 & 55.92 & 40.39 & 43.80 \\ 2023-24 & 227691 & 240323 & 212033 & 37.80 & 47.79 & 32.26 & 35.67 \\ 2024-25 & 240211 & 250026 & 265110 & 27.01 & 37.00 & 21.47 & 24.88\end{array}$

Scenario IV: CEA Projection (CEAS) - Based on fuel mix and demand suggested by Central Electricity Authority vide draft report on optimal generation capacity mix for 2029-30 (CEA, Govt of India $[17,18])$

\begin{tabular}{llllllll} 
CAGR \% & 6.44 & 2.66 & 17.90 & National & Central & State & Private \\
$2020-21$ & 193913 & 210592 & 102289 & 58.80 & 68.79 & 53.25 & 56.66 \\
$2021-22$ & 225751 & 216193 & 120599 & 68.15 & 78.14 & 62.60 & 66.02 \\
$2022-23$ & 238167 & 221944 & 142186 & 66.92 & 76.91 & 61.37 & 64.78 \\
\hline
\end{tabular}




\begin{tabular}{llllllll}
\hline $2023-24$ & 251267 & 227848 & 167637 & 64.93 & 74.92 & 59.39 & 62.80 \\
$2024-25$ & 265086 & 233909 & 197644 & 62.03 & 72.02 & 56.48 & 59.90
\end{tabular}

Scenario V (CEAS+PHOUT): CEA based projection and phasing out of old capacity. Based on fuel mix and demand suggested by Central Electricity Authority vide draft report on optimal generation capacity mix for 2029-30 (CEA, Govt of India [17,18]) and assuming that $5000 \mathrm{MW}$ old capacity will be phased out every year.

\begin{tabular}{llllllll} 
CAGR \% & 6.44 & $2.66 *$ & 17.90 & National & Central & State & Private \\
$2020-21$ & 193913 & 210592 & 102289 & 60.14 & 70.23 & 54.59 & 58.01 \\
$2021-22$ & 225751 & 216193 & 120599 & 70.84 & 80.93 & 65.29 & 68.71 \\
$2022-23$ & 238167 & 221944 & 142186 & 70.96 & 81.04 & 65.41 & 68.82 \\
$2023-24$ & 251267 & 227848 & 167637 & 70.32 & 80.41 & 64.77 & 68.19 \\
$2024-25$ & 265086 & 233909 & 197644 & 68.77 & 78.85 & 63.21 & 66.63 \\
\hline
\end{tabular}

* with $5000 \mathrm{MW}$ being phased out every year.

and $12.63 \%$ respectively. In Scenario II (RG), by 2024-25, the national PLF will reach $17.52 \%$, central, state and private sector will touch $27.51 \%, 11.97 \%$ and $15.39 \%$ respectively.

In Scenario III, Low Coal and Aggressive Renewable (LCAR), the national average PLF is projected at $27.01 \%$ in 2024-25. The central sector will maintain a 37.00\% PLF and state and private sectors will maintain $21.47 \%$ and $24.88 \%$, respectively. All these three scenarios show a grim picture with PLF dropping below $30 \%$.

In Scenario IV (CEAS), a slightly encouraging picture for thermal power stations emerges. This scenario considers coal capacity addition rate decelerated considerably to about $2.66 \%$ CAGR against current BAU rate of $6.04 \%$, the peak demand increase considered is steeper at $6.44 \%$ as compared to current CAGR of $5.5 \%$ (BAU) and Renewable Energy addition CAGR is considered reduced to $17.90 \%$ from current $23.03 \%$ (BAU). A combined effect of all the three independent variables on this path makes the national PLF to increase to $58.80 \%$ in the year 2020-21 itself. Under this scenario, by 2024-25, the PLF reaches $62.03 \%$. Central, state and private sectors are projected to operate at $72.02 \%, 56.48 \%$ and $59.90 \%$ respectively.

Scenario V, CEAS+PHOUT: In this case, the national PLF sustains at $68.77 \%$ by $2024-25$. central, state and private sectors are projected to operate at $78.85 \%, 63.21 \%$ and $66.63 \%$ respectively. This scenario assumes the conditions of scenario IV plus decommissioning of old plants at the rate of 5,000 MW every year. In this scenario, all the three segments (central, state and private) are able to maintain a reasonably high (above 60\%) PLF in the next five years. This is the most favourable scenario for thermal power plants.

\subsection{Sensitivity analysis}

The Jack-knife test has been used to find out the estimates of the three independent variables (Table 3). Using the estimates given by this method, it is found that if peak demand increases by 5,000 MW, the PLF will increase by $2.4 \%$ (4.9721e-04 × 5,000). If installed capacity of coal increases by $5,000 \mathrm{MW}$, the PLF will decrease by $1.35 \%(-2.6945 \mathrm{e}-04 \times 5,000)$ and if the total renewable energy capacity increases by 5,000 MW, the PLF will decrease by $1.36 \%$ $(-2.7133 \mathrm{e}-04 \times 5,000)$, taking $2019-20$ as base year. The highest impact is of peak demand 
(MW) in the positive direction $+2.4 \%$ / 5,000 MW, followed by total renewable energy (MW) in the negative direction (-) 1.36\% / 5,000 MW and then by installed capacity of coal (MW) again in the negative direction i.e. (-) 1.35\% / 5,000 MW.

\section{CONCLUSIONS}

There is urgent need to slow down new capacity addition and follow the projections made by CEA in their draft report on optimal generation capacity mix for 2029-30. Old and inefficient capacities should be phased out fast in a decisive manner. If the scenario IV or V is followed as detailed above, the thermal power plants would be able to sustain in the medium term with capacity utilisation above $60 \%$. This will enable them to recover their costs and sustain in the business. While considerable amount of renewable energy is being added, which is a welcome step, thermal power should not be left in the lurch. In the business as usual case (Scenario I), there is imminent risk of average national PLF falling to a very low level of $38 \%$ by 2022-23. In such a scenario, thermal power must be supported through policy incentives so that it can survive.

\subsection{Limitations of this paper}

Only three factors, namely (i) peak demand (MW), (ii) installed capacity coal MW and (iii) total renewable energy installed capacity (MW), have been considered as independent variables in our regression model. There could be other factors which have not been included and which might have enriched the model better. The paper also does not address the effect of low PLF on parameters like Sp. Oil Consumption, Auxiliary Power Consumption etc. Further, this paper has not considered the possible positive effects of new initiatives like Security Constrained Economic Dispatch (SCED) and Real Time Market (RTM) on capacity utilisation of thermal power plants. This paper also does not address as to what alternate uses can be there for the phased out (old) thermal power plant locations. These left out aspects could be avenues for future work.

\section{REFERENCES}

[1] Central Electricity Authority (CEA), Growth of Electricity Sector in India from 19472015 - www.cea.nic.in

[2] Central Electricity Authority (CEA), Annual Report - 2014-15 http://www.cea.nic.in/ reports/annual/annualreports/annual_report-2015.pdf

[3] Ministry of Power (MoP), Govt of India - http://powermin.nic.in/

[4] Ministry of Power (MoP), Working Group on Power - 12th Plan (2012-17), New Delhi, 2012.

[5] CEA Report- Growth of Electricity Sector in India from 1947-2017 http://www.cea. nic.in/reports/others/planning/pdm/growth_2017.pdf

[6] PTI, The Economics Times, Sept 16, 2020. https://energy.economictimes.indiatimes. $\mathrm{com} /$ news/power/total-capacity-of-under-construction-thermal-power-projects-at59810-mw/78138671

[7] Central Electricity Authority, National Electricity Plan 2018 (NEP), 2018. https://cea. nic.in/wp-content/uploads/2020/04/nep_jan_2018.pdf

[8] The Mint, India's growth rate for 2019-20 revised downwards to $4 \%$, Jan. 29, 2021. https://www.livemint.com/news/india/gdp-growth-rate-for-2019-20-revised-downwards-to-4-11611925568343.html 
[9] Verma, A.K., Financial Express, April 20, 2020. https://www.financialexpress.com/ opinion/the-dilemma-of-power-demand/1933598/ Accessed 06.04.2020

[10] Central Electricity Regulatory Commission, CERC, Terms and Conditions of Tariff Regulations, 2019, No. L-1/236/2018/, p. 60, March 7, 2019. http://www.cercind.gov. in/2019/regulation/Tariff\%20Regulations-2019.pdf

[11] Pandey, K., Lack of gas, high cost 'stranded' more than half of India's gas-based power plants, Down to Earth, Jan. 17, 2019.

[12] Russell, C., Coal going from winner to loser in India's energy future, Reuters, Feb 20, 2019. https://www.reuters.com/article/us-column-russell-coal-india/coal-goingfrom-winner-to-loser-in-indias-energy-future-russell-idUSKCN1Q90OP Accessed 06.09.2019

[13] Sharma, D. \& Soltendieck, R., Biomass Energy in India, Embassy of Denmark in India. https://indien.um.dk/en/innovation/sector-updates/renewable-energy/biomass-energyin-india

[14] Wang, P. \& Li, M., Scenario analysis in the electric power industry under the implementation of the electricity market reform and a carbon policy in China. Energies, 12(11), 2152, 2019. http://dx.doi.org/10.3390/en12112152

[15] Wang, Y. \& Chen, J., The environmental effect of capacity utilization in thermal power plants: Evidence from interprovincial carbon emissions in China. Environmental Science and Pollution Research International, 26(29), pp. 30399-30412, 2019. http:// dx.doi.org/10.1007/s11356-019-06251-2

[16] Smith, R.K., Analysis of hourly generation patterns at large coal-fired units and implications of transitioning from baseload to load-following electricity supplier. Journal of Modern Power Systems and Clean Energy, 7(3), pp. 468-474, 2019. http://dx.doi. org/10.1007/s40565-018-0470-9

[17] Central Electricity Authority, (CEA), Draft National Electricity Plan, Volume I, Dec. 2016. http://www.cea.nic.in/reports/committee/nep/nep_dec.pdf

[18] CEA, Draft report on optimal generation capacity mix for 2029-30, Feb. 2019. https:// img.saurenergy.com/2019/07/optimal_generation_mix_report-by-cea.pdf

[19] Sengupta, D., Thermal power plants' capacity utilization (PLF) to drop to $48 \%$ by 2022 , The Economic Times, Dec. 20, 2016. 